\title{
Why It's Good for Groups to Go Off-Task and Other Lessons from When by Daniel Pink
}

\section{George M. Jacobs}

Daniel Pink (Pink, 2018) is a bestselling author, popular TED ${ }^{\mathrm{i}}$ Talk speaker (Pink D. , 2009), and tv producer ${ }^{\mathrm{ii}}$. Much of his work is based on scholarly research on human behaviour. The purpose of the current review is to glean from his most recent book, When,ideas that might be useful for implementing cooperative learning (CL) in language teaching.

When is organised in seven chapters, and all but the final and shortest chapter is followed immediately by a companion 'Time Hacker's Handbook' section. This sections lists practical applications of the chapter's ideas to many aspects of time's impact on the lives of humans, but this review focuses solely on applications of research to CL in language teaching. Thus, if you want to know Dan's advice on such matters as when to exercise or when to get married, you'll have to read the book.

The lessons from Whenthat seem most relevant to $\mathrm{CL}$ in language teaching can be divided into three areas: restorative breaks, vigilance breaks, and motivation. Restorative breaks allow people to get their minds off what they are doing and get their bodies out of static seated postures. In other words, restorative breaks lead people off task. Here are some pointers - about half of which I have used and half of which I look forward to trying - on how to do restorative breaks in language classes, especially those using CL:

1. Even a mini-break is better than no break. For instance, students have a break when I use CL techniques in which some students move from one group to another, such as Everyone Can Explain Mobile

2. Move - even if it's doing chair yoga. "One study showed that hourly five-minute walking breaks boosted energy levels, sharpened focus, and 'improved mood throughout the day and reduced feelings of fatigue in the late afternoon"' (p. 61). The CL technique $7 \mathrm{~S}$ gets students out of their seats. The seven steps are:

- Stand (everyone stands up)

- Stretch (everyone does a stretch)

- Sip (everyone takes a sip from their water bottle)

- Slide (in classrooms with the appropriate furniture, students slide their chairs under their desks so as to provide more space for the next step)

- Stir (students walk around the room without their original group members)

- Stop (students stop walking and form a pair or threesome with a student from another group)

- Speak (the pairs discuss whatever topic has been decided upon).

3. Include a social aspect - "research in South Korean workplaces shows that social breaks - talking with co-workers about something other than work-are more effective at reducing stress and improving mood that either cognitive breaks (answering e-mail) or nutrition breaks (getting a snack)" (p. 62). CL, of course, already adds a social element to learning. 
4. Go outside if possible. If it's not possible, look out the window, at an indoor plant, or at a poster of a nature scene. Failing that, imagine being outside, perhaps accompanied by nature sounds.

5. Detach fully - Taking a walk outside with some groupmates while continuing to discuss the group task is not as beneficial as chatting about how your exercise regimen is going or the new vegan dish at a favourite restaurant. Such fully detached behaviour might be seen as "soft, frivolous, and antithetical to the head-down, laptop-up, inbox-zero ethos of the twenty-first century" (p. 63), but some research supports its use, and Pink includes $100 \mathrm{~s}$ of references. Sometimes, teachers feel pressure to cover so much material that they take away students' break time. I try to never do that.

6. Eat together-sharing food promotes bonding and performance. Drinking water is good, too. I sometimes give students treats, or I allow groups to bring tidbits to share among their members.

7. Meditate-http://marc.ucla.edu/mindfull-meditations.

8. Take some deep breathes. During breaks, I encourage students to take a few deep breathes.

9. Read, listen to, watch some jokes. There are two types of jokes, planned (such as showing a joke from the internet) and spontaneous (something funny happens in class and everyone laughs).

10. Maybe the most interesting idea - and one that fits with the literature on Positive Psychology - is to take a gratitude break by contacting people to express thanks to them. At the end of a CL activity or a class in which students have worked in groups, I often ask students to thank their partners. Even better is when students give each other specific praise.

All these ideas for restorative breaks link with what Salhberg (2017) advocated about students having regular recess breaks.

Vigilance breaks are a second type of way to spend time discussed in When. These breaks are similar to what David Johnson and his co-authors (e.g., Johnson \& Johnson, n.d.) have defined as an essential component of CL: processing group interaction, i.e., groupmates discussing the future, present, and past of their group's interaction as they strive to accomplish their shared goals. Here are some of Pink's pointers of helping groups monitor their effectiveness.

1. Do a "premortem" when groups begin their tasks (p. 107). Assume that rather than being at the beginning of the group's time together, it is the end, and things have gone badly. A premortem involves the group using "prospective hindsight" to figure out what went wrong in this hypothetical situation, and then, make plans to avoid the lurking pitfalls.

2. Set interim goals for individuals and groups, and make these goals public within the group and beyond.

3. Consider who will be helped if the group meets its goals. This echoes what Sharan and Sharan (1992) advocated in the Group Investigation method of CL, that students have the power to choose projects that synch with the students' own goals. How will students, their families, and others benefit from the students' increased language proficiency?

4. Try for a regular time to meet or at least communicate electronically, i.e., "don't break the chain" (p. 138). These regular 
meeting should, to the extent possible, be in the target language.

5. Use midpoints to assess how the group is functioning. To do this, first, the group needs to be aware of when the midpoint is and then pause to process. Language students especially need time to process what they have been studying.

6. Schedule time for a postmortem at the end of each session. "On good days, the exercise delivers feelings of completion; on bad days, it often shows me I got more done than I suspected" (p. 172). Part of this can include cooperative skills, such as encouraging others to participate and asking for repetition or reasons. These cooperative skills overlap with language functions.

7. When groups are going to disband, I often facilitate an activity in which each member tells/writes to every other member to share with them something that member did to enhance group functioning. The next time I do this activity, I hope to add the following idea from When (p. 164).

$[\mathrm{T}]$ he core of meaningful endings is one of the most complex emotions humans experience: poignancy [Ersner-Hershfield, Mikels, Sullivan, \&Carstensen, 2008), a mix of happiness and sadness. ... Adding a small component of sadness to an otherwise happy moment elevates (italics in original) that moment rather than diminishes it. ... The best endings don't leave us happy. Instead, they produce something richer - a rush of unexpected insight, a fleeting moment of transcendence, the possibility that by discarding what we wanted we've gotten what we need.

My favourite chapter was \#6, Synching Fast and Slow, a riff on the title of the book
Thinking Fast and Slow (Kahneman, 2011). One reason I especially enjoyed this chapter is that it is loaded with stories of groups with impeccable timing, including dabbawalas in Mumbai, who every day follow a very tight schedule to collect and deliver homemade lunches, and an amateur choir in Washington, DC that doesn't miss a beat. What drives these people to work consistently and well is something that CL strives to incubate in groups of students: a sense of belonging. "Belongingness, ... , profoundly shapes our thoughts and emotions. Its absence leads to ill effect, its presence to health and satisfaction" (p. 189). Two of the ways I strive to promote a feeling of belonging is by (1) helping everyone know and use their groupmates' names; and (2) suggesting that groups might want to choose a group name, motto, logo, handshake, proverb, mascot, etc.

Pink argued that more cohesion leads to more communication, even if it is chatting and gossiping, which, in turn, leads to more productivity. Some of Pink's suggestions for building cohesion resemble Johnson, Johnson, and Holubec's (2013) suggestions for promoting positive interdependence, e.g., environmental positive interdependence (i.e., groups sitting close together so that they can easily hear each other and see what everyone is doing), group celebration and rewards, unique resources for each group member, and individual, mutually dependent roles. Indeed, Wheneven has a few paragraphs about Jigsaw (Aronson, 2018).

Jigsaw has many variations, but in the basic version: (1) members of a group of four each read a different but related text, e.g., four different texts on what plant-based foods to eat to get various nutrients; (2) students leave 
their Home Group and form Expert Groups of four with students from different Home Groups who have the same text, and in the Expert Groups they collaborate to understand their text and make a plan to teach it to their Home Group members; (3) students return to their home group and each teaches; and (4) students take a quiz or do a task which requires knowledge from all four texts.

In conclusion, When provides an easy to understand and enjoyable to read assortment of suggestions that can help language teachers and students to reach their individual and collective goals in the classroom and beyond. Of course, implementing the book's suggestions will certainly prove more difficult that reading and understanding them. Perhaps, cooperation with others can help there. With what other language teachers will you collaborate to improve your timing in education?

\section{References}

Ersner-Hershfield, H., Mikels, J. A., Sullivan, Pink, D. H. (2018). When: The scientific S. J., \&Carstensen, L. L. (2008). Poignancy: Mixed emotional experience in the face of meaningful endings. Journal of Personality and Social Psychology,94(1),158167.doi: $\underline{10.1037 / 0}$ 022-3514.94.1.158

Johnson, D. W., \& Johnson, R. T. (n.d.). An overview of cooperative learning. Retrieved from: http://www.co-operation. org/what-is-cooperative-learning

Johnson, D. W., Johnson, R. T., \&Holubec, E. J. (2013). Cooperation in the classroom (8th ed.). Edina, MN: Interaction Book Company.

Kahneman, D. (2011). Thinking, fast and slow. New York, NY: Macmillan. secrets of perfect timing. New York, NY: Riverhead Books.

Pink, D. H. (2018). About Daniel Pink. Retrieved from Daniel Pink: https://www. danpink. com/about

Pink, D. (2009). The Puzzle of Motivation. TEDGlobal2009. Retrieved from https://www.ted.com/talks/dan_pink_on_ motivation

Sahlberg, P. (2017). FinnishED leadership: Four big, inexpensive ideas to transform education. Thousand Oaks, CA: Corwin.

Sharan, Y., \&Sharan, S. (1992). Expanding cooperative learning through Group Investigation. Colchester, VT: Teachers College Press.

\footnotetext{
'TED Talk previously refers to a conference in 1984 when Technology, Entertainment and Design were the main joined topics. Now that it becomes TED.com, the topics discussed are broad and varied.

iie.g., http://channel.nationalgeographic.com/crowd-control
} 